\title{
Perception of Satisfaction and Self-Confidence with High Fidelity Simulation Among Nursing Students in Government Universities.
}

\author{
Fatimah Aldhafeeri ${ }^{1}$, Dalayal Alosaimi ${ }^{2}$ \\ 1. Ministry of health, Saudi Arabia. \\ 2. Assistant Professor, Medical Surgical Nursing College of Nursing, King Saud University. \\ - E-mail of the corresponding author: fatma881@hotmail.com
}

\begin{abstract}
Background: High Fidelity Simulation (HFS) as a Teaching-Learning Methodology is usually implemented by the teaching institutions in the world. Several studies were conducted proving the significance of this method on improving the students' learning. With the several factors that hinder the students' clinical learning experiences, it is necessary to determine the students' viewpoint regarding the use of HFS in increasing their confidence and satisfaction.
\end{abstract}

Research Aim: The aim of this study is to assess the student perceptions regarding Satisfaction and self-confidence toward High Fidelity Simulation as a learning.

Research methodology: A cross-sectional correlation descriptive design was used in this study which was conducted at king Saud university (KSU) and princess Nourah university (PUN) in Riyadh. A quota stratified was used to recruit the participant female Saudi and non-Saudi BSN student with HFS experience who were asked to complete the questionnaire on student satisfaction and self-confidence regarding HFS in learning scale and the simulation design scale.

Results: This study found out that the fidelity (realism) is the most important factor in learning related to HFS. The students were satisfied and confident in utilizing HFS. Significant correlations between the profile of the participants' age and student academic level and the key of the simulation features were shown. It was also found out that there were significant correlations between age and marital status with self-confidence in learning through HFS.

Conclusion: Simulation as teaching method is as effective tool as a real-life without life-threatening of the patient and promoting students' performance. The fidelity of the simulation is the most important factor to the student and the students were satisfied and confident with current learning related to HFS. Future studies are needed to examine other learning outcomes such as clinical competence, motivation among student using HFS as a learning strategy. Keywords: high fidelity simulation, satisfaction, self-confidence.

DOI: $10.7176 / \mathrm{JEP} / 11-12-16$

Publication date: April 30th 2020

\section{Introduction:}

Nursing students and practitioners must be prepared and trained for innovative health care learning environment. In order to develop a continuous learning, personal, and professional skills to be in line with the rapid progress of science and knowledge, several colleges of nursing have integrated teaching and training curriculum within safe environment by using simulation.

High-fidelity simulation (HFS) has been used in nursing education over the world. Its effectiveness in student satisfaction and self-confidence among the undergraduate nursing students has been studied several times in the past. This is because simulation replicates the clinical situation to let the student recognize and manage the real clinical experience (Mortan, 1995).

High fidelity simulation is "a type of simulation that closely mimics reality by providing cosmetic fidelity, a realistic outward appearance of a live patient, as well as response fidelity, or the ability to simulate actual patient responses to interventions. High fidelity patient simulation (HFPS) are computerized manikins that duplicate the real patient and respond to the intervention by learner. These simulators actually breathe, talk, and have eye movements, palpable pulses, and other features that resemble physiologic features of actual patients (Smith, 2008).

Several studies were done that shows the positive impact of simulation to students who work with high fidelity patient simulation. A notable increase in their active learning and sense of responsibility in their practice were just among those positive effects. HFS have a great value in their learning experience with a great confidence and satisfied in ability of caring patient (Jeffries et al., 2006).

The academic institutions play central role in developing and applying new training modalities to health 
care in Saudi Arabia (Arab et al. 2017). Many studies were conducted in Saudi Arabia regarding simulation describing the usage of simulation, outcome of using simulation as well as satisfaction and confidence (Arab et al.2017; Omer, 2016; Abozaid, 2017).

In the study conducted by Tutticci et al. (2016), HFS was found as the most learning style favored by the students offering a solution to the problem faced by the participant and their responses toward simulation (Tutticci et el., 2016). Through simulation scenarios programmed in the HFS, Kaddoura et al. (2016) stated that the student recognizes the patient needs, implement effective nursing procedures, and shows communication skills integrated with the situation (Kaddoura et al., 2016). Students perceived that they gain a high level of knowledge with the use of HFS (Baptista et al. 2016) and have realized that through simulation, it is acceptable to ask for help. Furthermore, good communication and team effort are needed for patient care (Lestander et al., 2016).

The simulation can be applicable option in provide in providing a clinical experience for nursing students (Zapko et al., 2018). As cited by (Tosterud, 2015), the simulation should be integrated at different levels in general nursing education by using proper methodologies and take different learning approaches necessary for community learning. Zapko et al. (2018) found out that Serial simulation experience is an effective and valuable method as a learning tool (Zapko et al., 2018; Kaddoura et al. 2016).

The use of high fidelity simulation motivates and increase the student passion to learn. Lubbers and Rossman (2017), revealed that novice students were highly satisfied with the fidelity of the simulation experience (Lubbers and Rossman, 2017). This has resulted to a suitable (Au et al. 2016; Woodruff et al. 2017), realistic (Kirkpatrick et al., 2018; Tutticci et al., 2016), resulting to a positive clinical experience because it imposes no risk to the patients (Omer, 2016). It has been suggested that implementation of the clinical simulation must be effective and applicable option to guide the clinical experiences and must be applied in all clinical courses by using multiple simulations before clinical practice (Kaddoura et al., 2016)

Multiple studies have been conducted that compared the student's satisfaction with the utilization of high, moderate and low fidelity simulators. According to Basak et al. (2016), and Baptista et al. (2016) high-fidelity mannequins had more influence on student satisfaction and self-confidence than low fidelity (Basak et al., 2016; Baptista et al., 2016). However, even with medium fidelity simulation, students' self-confidence and satisfaction can also increase, and additional knowledge were gained in using simulation (Lubbers and Rossman, 2017) .

The use of HFS results to the development of their critical thinking skill, clinical competence, integrated knowledge into clinical situations and enhanced self-confidence in implementing nursing care in a safe environment with multiple health conditions (Lewis et al., 2012). Previous studies indicated the different level of satisfaction regarding the use of HFS. Baptista et al. (2016), found that the students were very satisfied, and the gain perceived by nursing students was high, however, in the study of Mariani and Doolen (2016), students were satisfied with the simulation. Several previous studies have proven the positive effect of the use of HFS in the clinical education. This teaching methodology has improved student satisfaction, self-confidence (Kaddoura et al. 2016; Mariani and Doolen, 2016; Badir et al. 2015) , self-efficacy (Warren et al. 2016; Mariani and Doolen, 2016), developed their skills (Cummings and Connelly, 2016; Omer, 2016) and increase team member's cooperation by working well together, recognizing individual differences. Tutticci et al. (2016) found out that students become more aware on their gap in their knowledge (Tutticci et al., 2016). Abozaid (2017), demonstrated that only fidelity was independently associated with both satisfaction and self-confidence, however, gender and age are not correlated with satisfaction and confidence with the students' simulation experience. This is so, since the participants had the same simulation experience, medical background and close in age between the participant (Abozaid, 2017).

The use of simulation has been widely used as a teaching learning method, especially in the college of nursing. With the repetitive performance of objectively evaluated skills through simulation, students gain more confidence in the care of actual patients in the clinical area in terms of decision making in a certain situation, improves in depth learning, professional skills and responsibilities. According to Lestander et al. (2016), the confidence and self-knowledge grew when the students handle patients with varied conditions and has improved patient outcome. The student expresses that their confidence is increased when they have the knowledge and skill to manage the situation (Lestander et al., 2016). High-fidelity simulation also constructs professional skills and assist to transfer theory into practice. HFS has also proved its use in gaining professional knowledge and skills within a realistic clinical experience in an intra professional peer learning simulation (Badir et al., 2015). Kirkpatrick et al., 2018) revealed that BSN students showed high skill performance, collaboration, confidence, and leadership with simulation. According to the students, their clinical learning was enhanced, communication and understanding of interdisciplinary roles were strengthened by peer learning in Simulation, especially if feedback were provided to them. Because Simulation as a training method improves knowledge (Kirkpatrick et al., 2018) and confidence in critical care and may fill up deficiencies in the provider's clinical experience, it is 
considered to be more effective than actual patient care in some cases. (Boling and Hardin-Pierce, 2016). In addition, Lewis et al. (2012), cited that simulation helped to develop student self-efficacy and confidence, improved interpersonal skills in communication, teamwork, leadership, and decision-making, interpersonal communication at patient handover, and a progress in team behavior associated with team performance in crisis. In Nursing, cognitive skills utilizing different tools in a complex situation has improved critical thinking and critical reasoning (Lewis et al., 2012).

\subsection{Conceptual Framework:}

This study is anchored on the concept of Jeffries $(2005,2007)$ related to the nursing education simulation framework which was designed to show the participation of teacher and student in integrating educational practices to help in designing, implementing, and evaluating simulation.

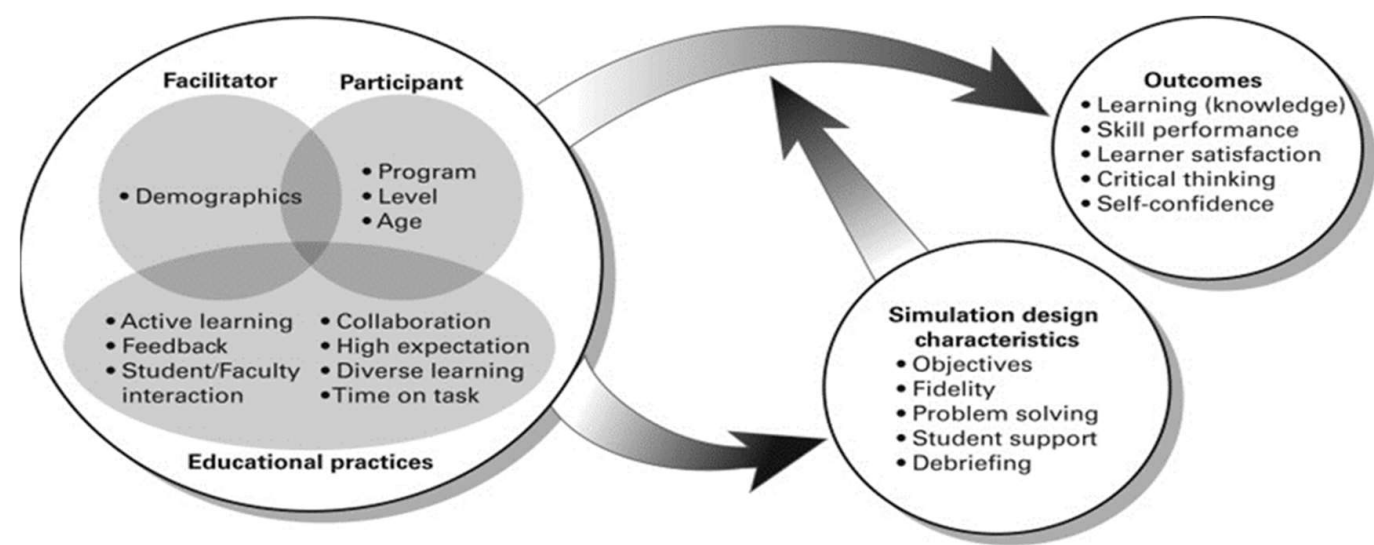

Figure 1. Determinants of Student Satisfaction and Self Confidence related to High Fidelity Simulation

In this model, both the facilitator (teacher) and the participant (students) work together so that students will acquire competencies based on curricular requirements. Educational practices such as active learning, feedback given through faculty student interaction, collaboration, high expectation, diverse learning and timed tasks are accomplished through collaboration between student and faculty.

The teacher as the facilitator motivates and corroborates with the learner. The participant (student), as the active learner, must be given the right to learn and be given a chance to find answers without being instructed by the teacher. The learner is self-directed and in charge of their teaching in safe secure, simulated environment. The framework has five major components: educational practices influence the participant's simulation design which in turn affect the Outcomes such as learning, skill performance, satisfaction, critical thinking and self-confidence (King, 2012). However, in this study, the researcher only focused on the two dimensions, out of five, which are self-satisfaction and self-confidence as learning outcomes developed through the use of simulation.

The simulation environment provides real-life situations to develop knowledge, skills and values essential for nursing care. Students evaluate the simulation as learning tools, concerning their level of satisfaction, improvement in self-confidence and learning performance. The simulation teaching environment can be successful when the student is more confident (Aljohani et al., 2016). The simulation assists to measure skills, performance, acquire competence before performing care to an actual patient, and test new device before using on actual patient integrating patient safety principles within training program.

The aim of this study is to assess the students' perceptions regarding satisfaction and self-confidence toward high Fidelity simulation as a learning strategy and the significant relationship between the nursing student perception as well as satisfaction and self-confidence with HFS based on the profile variables.

\section{Materials and Methods}

\subsection{Research Questions.}

To fulfill this, aim the following questions will be answered:

1. What is the student's perceptions toward HFS as a learning strategy?

2. What is the level of satisfaction and self-confidence of nursing students using HFS?

3. Is there any correlation between students' perceptions of key simulation features and the profile of the 
participants?

4. What is the relationship between the student perception of satisfaction and self-confidence in using HFS based on the profile of the participant?

\subsection{Ethical Consideration:}

1. The study proposal was approved by king Saud university council and the researcher has a written approval from the institutional review board (IRB) of faculty of nursing, at king Saud university, and princess Nora university .

2. The participants were provided with the instrument that contained an explanation of the study and its purpose and method. The required instructions were given and explained to the participants.

3. Written consent was obtained from all participants.

4. The respondents were treated with anonymity wherein questionnaires were filled with no link to their names or identification numbers.

5. Participation were voluntary, and participants were notified that they can withdraw from the study at any time without affecting their right.

6. All answers were maintained with confidentiality during data collection and processing, and that the collected information was not used outside the terms of the agreement.

7. The research was conducted at king Saud university and princess Noura university in Riyadh city, utilizing female nursing students.

2.3. Research Design:

A cross-sectional correlation descriptive design was used in this study.

2.4. Study Setting:

The research was conducted at king Saud university (KSU) and princess Nourah bint Abdulrahman university (PNU) in Riyadh who uses HFS.

\subsection{Subjects:}

\subsubsection{Sample Type:}

In this study, A quota sample technique has been used, where the study population was divided into two strata: first group of female nursing students of the university of princess Nourah bint Abdulrahman and the second group from king Saud.

\subsubsection{Sample Size:}

A total population of 404 level five to eight students from bachelor of science in nursing (BSN) program were identified from king Saud university (KSU) and princess Nourah bint Abdulrahman university (PNU) for the academic year 1438- 1439. Students included in this study were 186 students from KSU and 218 from PNU. Students who participated in this study were from level five to eight bachelor of science in nursing (BSN) program from king Saud university and princess Nourah bint Abdulrahman university, where KSU had 186 and PNU had 218 students.After the students were informed about the study, 54 from KSU and 78 students from PNU volunteered and participated in this study

\subsubsection{Statistically Calculated Sample Size from the Population:}

In selecting units from any stratum, the sample size was calculated based on probability proportional to size (PPS) technique, where:

$$
\begin{aligned}
& \mathrm{n}=\{(\mathrm{z}) 2 *(\mathrm{p})(\mathrm{q})\} /(\mathrm{d}) 2 \\
& \mathrm{P}=0.5 \text { population proportion Use } 50 \% \text { if not sure } \\
& \mathrm{q}=(1-\mathrm{p})
\end{aligned}
$$




$$
\begin{aligned}
& \mathrm{d}=8.5 \%(8.5) \text { the margin of error } \\
& \mathrm{Z}=1.96 \text { as } 95 \% \text { confidence level } \\
& \mathrm{n}=132
\end{aligned}
$$

Therefore, with the probability proportional to size (PPS) technique employed, where KSU consists of 40.9\% (n $=54)$ and $59.1 \%$ from PNU $(\mathrm{n}=78)$ has garnered the total sample size $\mathrm{n}=132$.

\subsubsection{Sample Criteria:}

Inclusion and exclusion criteria:

Inclusion criteria: The samples include Level 5-8 female Saudi and non-Saudi BSN student in KSU and PNU with HFS experience.

Exclusion criteria: male students, female Students from Level 3-4 as well as master students.

2.6. Tools:

2.6.1. The Instrument:

A self-report method involving questionnaire completion was applied. The structured questionnaire consisted of two parts:

Part A pertains to the items on demographic variables like age, level, civil status, and nationality

Part $\mathbf{B}$ tackles about student satisfaction and self-confidence which are measured using two instruments developed by the national league for nursing (NLN): student satisfaction and self confidence in learning scale and the simulation design scale (national league for nursing, 2016). These instruments were used to assess student's perceptions toward simulation as a learning strategy (Franklin et al., 2014).

Tool No. 1: The Simulation Design Scale (student version) (national league for nursing, 2016), is a 20-item instrument using a five-point scale, where 1 is interpreted as strongly disagree, 2- disagree, 3 - undecided (neither agree or disagree with the statement), 4- agree, 5- strongly agree and NA - not applicable where the statement does not pertain to the simulation.

This tool was designed to evaluate the five design features of the instructor-developed simulations used in the NLN/Laerdal study. The five design features include: 1) objectives/information; 2) support; 3) problem solving; 4) feedback; 5) fidelity. The instrument has two parts: the first part pertains to presence of specific features in the simulation, and the second part is related to the importance of those features to the learner.

Tool No. 2: student satisfaction and self-confidence in learning (national league for nursing, 2016), a 13-item instrument was designed to measure student satisfaction with the simulation activity (five items) and selfconfidence in learning (eight items) using a five-point scale. Five-point Likert scale was utilized where 1 is interpreted as $1=$ strongly disagree, $2=$ disagree, $3=$ undecided $4=$ agree with and $5=$ strongly Agree with the statement.

2.6.2. Tool Validity and Reliability:

The standardized questionnaire has undergone Content validation for the simulation design scale (student version) which was previously established by ten content experts in simulation development and testing. The instrument's reliability was tested using Cronbach's alpha, which was found to be 0.92 for presence of features, and 0.96 for the importance of features (national league for nursing, 2016). Reliability was also tested using Cronbach's alpha: satisfaction $=0.94$; self-confidence $=0.87$ for student satisfaction and self-confidence in learning (national league for nursing, 2016).

The two tools utilized were downloaded in an open access journal and permission is no longer necessary as what is stated in the questionnaire.

2.7. Methods of Data Collection:

Before data collection was initiated, the proposal was sent to the supervisors of the medical surgical department, in both male and female section, where it was presented to the panel. After recommendations were considered, and approval was granted, the researcher submitted the proposal to the institutional review board (IRB) of faculty of nursing, at king Saud university, and princess Nora university .

Before the questionnaires were distributed to the students, ethical considerations were discussed, and the concept of anonymity and voluntary participation were emphasized. They were asked to complete two instruments developed by NLN, the simulation design scale and satisfaction and self-confidence.

2.8. Method of Data Analysis:

1. The data has been categorized, coded and analysed according to the suitable statistical method using Statistical 
Package for Social Sciences, SPSS v. 25 (SPSS Inc, IBM).

2. Descriptive statistics have been used to describe the sample variables frequencies, means, standard deviations, minimum-maximum and percentage, tables and figures have been made.

3. Statistics with confidence intervals $(95 \%)$ were established for parameters of the study; p-value significant at $<0.05$. In addition, chi-square was used to compare between variables.

\subsection{Conflict of Interest:}

This research did not receive any specific grant from funding agencies in the public, commercial, or not-for-profit sectors.

\section{Results:}

Table 1. Profile of the Respondents: $n=132$

\begin{tabular}{|c|c|c|c|}
\hline & $\mathrm{KSU}$ & PNU & \\
\hline & Frequency & Frequency & Percentage \\
\hline \multicolumn{4}{|l|}{ Age } \\
\hline 20 & 11 & 9 & 15 \\
\hline $21-25$ & 28 & 64 & 69.7 \\
\hline $26-30$ & 13 & 5 & 13.6 \\
\hline $31-35$ & 2 & 0 & 1.5 \\
\hline \multicolumn{4}{|l|}{ Level } \\
\hline Level 5 & 8 & 10 & 13.6 \\
\hline Level 6 & 8 & 34 & 31.8 \\
\hline Level 7 & 8 & 10 & 14.4 \\
\hline Level 8 & 30 & 24 & 40.2 \\
\hline \multicolumn{4}{|l|}{ Civil status } \\
\hline Single & 44 & 73 & 88.6 \\
\hline Married & 10 & 5 & 11.4 \\
\hline \multicolumn{4}{|l|}{ Nationality } \\
\hline Saudi & 51 & 78 & 97.7 \\
\hline Non-Saudi & 3 & 0 & 2.3 \\
\hline Total & $54=40.9 \%$ & $78=59.1 \%$ & 100.0 \\
\hline
\end{tabular}

Table 2: Response Rate

\begin{tabular}{|l|l|l|l|}
\hline University & Distribution & collected & Analysis \\
\hline KSU & 58 & 54 & $93.10 \%$ \\
\hline PNU & 80 & 78 & $97.5 \%$ \\
\hline
\end{tabular}

3.1. What is the Student's Perceptions Toward HFS as a Learning Strategy?

This study found out that the students believes the fidelity (realism) is the most important factor in learning related to HFS. 
Table 3: Summary of Subtopics on Students' Perception Towards High Fidelity Simulation as a Learning Strategy

\begin{tabular}{|c|c|c|c|}
\hline Items & Mean & Std. Deviation & Interpretation \\
\hline Objectives and Information & 3.77 & 0.860 & Agree \\
\hline Support & 3.64 & 0.954 & Agree \\
\hline Problem Solving & 3.69 & 0.983 & Agree \\
\hline Feedback / Guided Reflection & 3.82 & 1.063 & Agree \\
\hline Fidelity & 3.95 & 1.145 & Agree \\
\hline Composite Mean & $\mathbf{3 . 7 8}$ & $\mathbf{1 . 0 0 1}$ & Agree \\
\hline
\end{tabular}

Legend: Strongly Agree (4.2-5.00); Agree (3.4-4.19); Undecided (2.6-3.39); Disagree (1.8-2.59); Strongly disagree (1.0-1.79)

3.2. What is the Level of Satisfaction and Self-Confidence of Nursing Students Using HFS? The students were satisfied and confident in utilizing HFS.

Table 4: Level of Satisfaction and Self-Confidence of Nursing Students using High Fidelity Simulation $\mathrm{n}=132$

\begin{tabular}{|c|c|c|c|}
\hline Items & Mean & Std. Deviation & Interpretation \\
\hline Level of Satisfaction & 3.73 & 1.002 & Satisfied \\
\hline Level of Self Confidence & 3.64 & 0.792 & Confident \\
\hline
\end{tabular}

Legend: Very satisfied / Confident (4.2-5.00); satisfied/ Confident (3.4-4.19); Undecided (2.6-3.39); Dissatisfied/In confident (1.8-2.59); Strongly Dissatisfied / very in confident (1.0 -1.79)

3.3. Is There Any Correlation Between Students' Perceptions of Key Simulation Features and the Profile of the Participants?

Significant correlations between the participants' age and Problem Solving; students' Level with Objectives and Information, Support, and Fidelity. Marital Status has shown no significant correlations with all of the simulation Features.

Table 5: The correlation between students' perceptions about key simulation features and the profile of participants.:

\begin{tabular}{|l|c|c|c|c|c|c|}
\hline & \multicolumn{2}{c|}{ Age } & \multicolumn{2}{c|}{$\begin{array}{c}\text { Student academic } \\
\text { Level }\end{array}$} & \multicolumn{2}{c|}{ Marital Status } \\
\hline \multicolumn{1}{|c|}{ Items } & Chi square & p value & Chi square & p value & Chi square & p value \\
\hline \hline Objectives and Information & 221.673 & .456 & 80.763 & $.038^{*}$ & 11.085 & .944 \\
\hline Support & 158.421 & .982 & 80.655 & $.011^{*}$ & 15.160 & .651 \\
\hline Problem Solving & 256.583 & $.046^{*}$ & 77.558 & .063 & 14.471 & .806 \\
\hline Feedback/Guided Reflection & 208.551 & .496 & 64.493 & .231 & 11.372 & .911 \\
\hline Fidelity (Realism) & 111.477 & .443 & 53.237 & $.006^{*}$ & 9.869 & .452 \\
\hline
\end{tabular}

3.4. What is the Relationship Between the Student Perception of Satisfaction and Self-Confidence in Using HFS Based on the Profile of the Participant?

Significant correlations exist between age and marital status with self-confidence in learning. 
Table 6: The relationship between the student perception of satisfaction and self-confidence in using HFS based on the profile of participant:

\begin{tabular}{|l|c|c|c|c|c|c|}
\hline & \multicolumn{2}{|c|}{ Age } & Student Academic Level & \multicolumn{2}{c|}{ Marital Status } \\
\hline \multicolumn{1}{|c|}{ Items } & Chi square & p-value & Chi square & p-value & Chi square & p-value \\
\hline $\begin{array}{l}\text { Satisfaction with Current } \\
\text { Learning }\end{array}$ & 68.164 & .942 & 34.039 & .084 & 5.529 & .700 \\
\hline $\begin{array}{l}\text { Self-confidence in } \\
\text { Learning }\end{array}$ & 374.200 & $.000^{*}$ & 94.794 & .095 & 42.691 & $.021^{*}$ \\
\hline \hline
\end{tabular}

\section{Discussion:}

Nursing students often verbalizes their anxiety as they go the clinical. In order to improve nursing student's clinical skills and overcome students' negative experiences, Simulation can be employed to create experiential student-centered training environments practice (Singlair and Ferguson, 2009), (Jeffries, 2012).

\subsection{Students' Perception Towards High Fidelity Simulation as a Learning Strategy:}

The results of the current study revealed that fidelity $(\mathrm{m}=3.95)$ was ranked as the highest out of the five features of simulation. Students agree that fidelity in simulation denotes real-life factors, situations and variables were built into the simulation scenario. This result is supported by the study of Woodruff, O'Neill, and WaltonMoss (2017) in which the students were undecided that fidelity (realism) was sufficiently realistic. According to Kneebone (2003) and Ziv et al. (2003), who stated that students are provided with substantial learning experiences through simulation based training, were given the opportunity to engage in hands-on experience, and can practice a set of specific knowledge and skills without potentially harming the patients.

On the same line of the current study result (Badir et al. 2015) emphasize that Fidelity as a feature in simulation involves a realistic clinical experience with HFS which helps students improve the professional knowledge , skills and values essential for nursing care.

Another feature in Simulation is related to feedback or guided reflection $(\mathrm{m}=3.82)$. Students agree that simulation made them analyze their own behaviors and actions. Reflection as one of the features of HFS enables individuals to recall the events that have transpired, comprehend and convert them into a learning experience. Simulation allows the students to practice their skills repeatedly, and to learn from their own mistakes within a safe environment (Gaba, 2000; Kneebone, 2003).

The result of this study revealed that students rated support as the lowest simulation design elements with mean of 3.64. Students agree that the Support offered in the simulation activity was given by the faculty in a timely manner. Woodruff et al. (2017) cited that students depended on the support given by the faculty and revealed that students without experience got a lower support compared with student's who have experience.

The study findings consist with Tanner's clinical judgment model (2006) of noticing, interpreting, responding, and reflecting where the students' overall perception of HFS was very positive. Using this model along with HFS, nursing educators can provide feedback and training to novice students where they have knowledge deficits. In this way, students will develop their own clinical thinking and clinical judgment through specific learning activities. (Jaffer et al., 2015).

\subsection{Level of Satisfaction and Self-Confidence of Nursing Student Using HFS:}

As regards the level of satisfaction of nursing students the current study result shows a mean of satisfaction 3.73 as compared to self-confidence which has a mean of 3.64. This means that, although the student is satisfied with HFS they have less self-confidence in relation to the application of procedure in real life situation. However, this study contradicts the study of Woodruff et al. (2017) students were undecided that they are satisfied toward simulation as a learning strategy. It has been emphasized that simulation has improved student satisfaction in learning (Kaddoura et al. 2016; Mariani and Doolen, 2016; Badir et al. 2015). Moreover, this study revealed that Students agree that the teaching materials used in simulation was helpful and motivated them to learn and that various learning materials and activities are provided to promote learning the Medical Surgical curriculum. Kuzznar (2007) revealed in his study that students in the associate degree nursing were highly satisfied with HFS and the knowledge about students' satisfaction in HFS is a significant step in measuring the utilization of HFS in nursing education.

Student's self-confidence in learning obtained a mean value of 3.64. Findings suggests that students agree that their instructors used helpful resources to teach the simulation. According to the students, simulation includes critical content necessary for the mastery of medical surgical curriculum. This finding is not similar with that of 
Woodruff et al. (2017) where students were undecided that they are confident toward simulation as a learning strategy.

Furthermore, this finding is true with the study of Zapko et al. (2018) which supports that the simulation contributes to positive learning experience. Simulation has improved student self-efficacy (Warren et al. 2016; Mariani and Doolen, 2016), developed their skills (Cummings and Connelly, 2016; Omer, 2016) and increase team member's cooperation by working well together, recognizing individual differences. Also, Tutticci et al. (2016) found out that students become more aware about their gap in their knowledge.

In the same line of the current study result and according to (Kirkpatrick et al. 2018), simulation as training method improves knowledge and confidence in critical care and may fill up deficiencies in the provider's clinical experience, it is considered to be more effective than actual patient care in some cases. Boling and HardinPierce, (2016) and Woodruff, O’Neill, and Walton-Moss (2017) confirm that implementation of the clinical simulation must be effective and applicable option to guide the clinical experiences and must be in applied in all clinical courses by using multiple simulations before clinical practice (Kaddoura et al., 2016).

Additionally, the result of the current study is congruent with to Lewis, Strachan, and Smith (2012), who emphasized that simulation helped to develop student self-efficacy and confidence, improved interpersonal skills in communication, teamwork, leadership, and decision-making, interpersonal communication at patient handover, and a progress in team behavior associated with team performance in crisis was observed.

4.3. Regarding the Correlation Between Students' Perceptions About Key Simulation Features and the Profile of Participants.:

The finding of this study reveals significant correlations between age and problem solving with $\mathrm{p}=0.04$. It implies that as the age matures the level of problem-solving increases. Student's age is significantly correlated with problem solving only as compared to the other features of the Simulation design Scale. This indicates that with age, students become more concerned about the decisions and priorities in nursing assessment. With simulation, students explore all possibilities, and facilitates their independent problem solving.

This result is consisting with Lioce et al (2015) and Tutticci et al. (2016) who stated that the millennial generation may apply theory learned to HFS scenario more smoothly than other generations, enabling a more rapid assimilation of theory to practice. Other generations may require assistance to meaningfully translate theory into clinical practice

Moreover, As revealed from this study finding, a relationship exists and indicates that the students' perceptions about key simulation features as to objectives and information, support and fidelity was affected by the respondent's year level. Thus, the higher the level of the students, the more that their perceptions increases on the above-mentioned variables. In the concern, Tutticci et al. (2016) stated that High fidelity is valued by third year nursing students, irrespective of their leaning styles participants were highly satisfied and agreed that effective teaching and learning strategies were evident and important for simulation

As regard the current study findings concerning with students' academic level students in each level has different specialization and different focus of care across the life span. Students from lower level starts with concepts related to medical surgical nursing where basic nursing procedures were performed. In this level, students need to be oriented with the objectives and significant information related to the use of Simulation in enhancing learning. Faculty support is a significant factor in student learning especially if these students are in the lower levels and are learning the basics of nursing care. Creating realistic scenarios will assist the students to acquire confidence as they handle the actual patient in the clinical areas. This is supported by the Woodruff et al. (2017), who cited that students' level is significantly correlated with Support and is more concerned with the simulation activity given by the faculty in a timely manner. Students without experience got a lower support compared with student's who have experience.

On the other hand, with all of the participant's profile, marital status was found out to have no significant relationship with all of the key simulation features. This means that Simulation is perceived by both groups of respondents as significant in learning. whether the student is single or married.

4.4. As Regards the Relationship Between the Student Perception of Satisfaction and Self-Confidence in Using HFS Based on the Profile of Participant:

The findings of this study revealed that students' perception of satisfaction has no significant relationship with the profile of the participants. With regards to the profile and self confidence in learning, it was only the student's level which is not significantly related with the level of confidence. However, age $(\mathrm{p}<0.000)$ and marital status $(\mathrm{p}=.021)$ showed significant relationships with the level of self-confidence in learning. This signifies that 
younger students who are single, have a lower degree of self confidence in learning through Simulation. They perceive that it is the instructor's responsibility to teach them what they need to learn in the simulation activity more than the older ones.

The finding of this study was supported by Alammary (2017), Smith (2008), King (2012), and Abozaid (2017) who discussed that the student's age has no statistical significant correlation with satisfaction. This finding is opposed by (Omer, 2016) who proved that the student's age is significantly correlated with student's satisfaction in learning.

Also, the finding of this study revealed that there was no significant relationship existing between student academic level of nursing student and satisfaction in learning. This finding was supported by Smith (2008), who added that specifically during the first, second and third semester, significant correlation does not exist between student satisfaction and student level. This was opposed by Alammary (2017), Smith (2008), and King, (2012), who discussed that the student satisfaction with learning had a statistically significant correlation with the educational level. This varying finding of the studies could be accounted to the individual differences of each student and their perception of the simulation features.

As to the existing significant relationship between age and self confidence in this study, the findings indicates that a younger student can be satisfied but still not confident enough to perform in Simulation learning activities. Alammary (2017), Smith, (2008) and King, (2012), Omer (2016), and Abozaid (2017), opposed that the student's age has no statistical significant correlation with self-confidence. This could also be true since the participants had the same simulation experience, medical background and close in age between the participant.

Regarding marital status, single students often adjusting personally as well as with social integration compared to married students, (Astin, 2016; Lenning 2015). Astin (2016) indicated that marriage, before or while in college, tends to decrease women's chances of perseverance, and that marriage was the most common reason given by women for leaving school. Astin (2016) reported that marital effects on career development for women can be substantially reduced if women can remain in school.

\section{Conclusion:}

The results demonstrated that students agreed that fidelity in simulation denotes real-life factors, situations and variables were assembled into simulation scenario. Students approve that the teaching materials used in simulation was supportive and inspired them to learn. They also agree that several learning resources and activities are provided to help learning the Medical Surgical curriculum. Student's age is significantly associated with problem-solving only when compared to the other features of the simulation design scale. The results also shown that students' perception of satisfaction has no significant linked to the profile of the participants. With regards to the profile and self-confidence in learning, it was shown that only the student's level is not significantly associated with the level of confidence. Simulation as teaching method is as effective tool as a real-life without life-threatening of the patient and promoting students' performance. The fidelity of the simulation is the most important factor to the student and the students were satisfied and confident with current learning related to HFS.

\section{Recommendation:}

6.1. Recommendation for Nursing Education:

1. It is recommended that student's learning styles and characteristics should be assessed and evaluated.

2. Further researches are required to identify strategies that will enable the nurse educators to promptly identify and respond to student learning styles and characteristics.

3. There is need also to explore the sustainability of the impact of simulation and since they are satisfied with HFS experience, the reason of this level of satisfaction after the simulation is not known and can be studied further.

6.2. Recommendation for Nursing Practice:

1. More research is needed to examine the transferability of the impact from the simulation experience into the clinical setting and utilizing a larger sample size.

2. More support the students during simulation will increase student's skill performance and knowledge.

3. Encouraging them to explore all possibilities of the simulation and Independent problem solving being facilitated thru Simulation.

6.3. Recommendation for Nursing Administration:

1. There is a need to examine other learning outcomes such as clinical competence, motivation and learning knowledge and may be evaluated with all levels of nursing students.

2. nursing faculty needs to consider students perception about the simulation when designing, performing, and evaluating simulation activities.

6.4. Recommendation for Nursing Research: 
1. A comparative study to be done in different regions in Saudi Arabia between government and private universities 2. Another outcome of the simulation design that are suggested to be evaluated are Skill Performance, Critical Thinking, and knowledge.

3. Correlation between the outcomes and other items in the Nursing Education Framework should be determined as these will be a great value in nursing education.

\section{Limitation of the Study:}

1. Limitations of this study included having conducted only in two government universities in Riyadh, focusing on female students.

2. In addition, this study evaluated only two outcomes such as satisfaction and self-confidence in the utilization of HFS.

3. Other outcomes were not evaluated like skill performance, critical thinking, and knowledge which are important aspects of nursing education.

\section{Acknowledgement}

The author would like to show her gratitude to Dr. Irene Roco (Assistant Professor, King Saud University) for provided insight and expertise that greatly assisted during the course of this study. The author also thanks Dr. Nadia Baghdadi (assistant professor, princess Nourah bint Abdulrahman university) for her continuous advice that greatly improved this study. Finally, The author thanks Mrs. Tufra Alenzi (princess Nourah bint Abdulrahman university) for her assistance during sample collection related to this study.

Fatimah Mana Aldhafeeri has completed her Master Degree from King Saud University in Riyadh. She is a nurse spicalist in ministry of health, Saudi Arabia. She has been working in the health care system for 17 years and held several position.

Dr. Dalayal Alosaimi is an assistant professor in medical surgical nursing college of nursing in king Saud university.

\section{References:}

Abozaid, Hani. (2017). Students ' Satisfaction Regarding Simulation At Medical College, Taif University, Saudi Arabia. International Educational Scientific Research Jounral, 3(4).

Alconero-Camarero, AR., Sarabia-Cobo, CM., Gonzalez-Gomez, S., Ibanez-Rementeria, I., Lavin-Alconero, L., Sarabia-Cobo, AB. (2017). "Nursing Students' Emotional Intelligence, Coping Styles and Learning Satisfaction in Clinically Simulated Palliative Care Scenarios: An Observational Study." Nurse Education Today, 61.

Au, ML., Lo, MS., Chenog, W., Wang, SC., Van, IK. (2016). Nursing Students' Perception of High-Fidelity Simulation Activity Instead of Clinical Placement: A Qualitative Study. Nurse Education Today, 39.

Aljohani, AS., Karim, Q., and George, P. (2016). Students' Satisfaction with Simulation Learning Environment in Relation to Self-confidence and Learning Achievement. J. of Health Science, 4(5).

Alammary, MA. (2017). Saudi novice undergraduate nursing students' perception of satisfaction and selfconfidence with high-fidelity simulation: A quantitative descriptive study. Saudi Crit Care J;1.

Arab, A., Alatassi, A., Alattas, E., Alzoraigi, U., AlZaher, Z., Ahmad, A., and Boker, A. (2017). Integration of simulation in postgraduate studies in Saudi Arabia: The current practice in anesthesia training program. Saudi Journal of Anaesthesia, 11(2).

Badir, A. et al..(2015). Using High-Fidelity Simulation as a Learning Strategy in an Undergraduate Intensive Care Course. Nurse educator, 40(2).

Baptista, C.N. et al. 2016. Satisfaction and Gains Perceived by Nursing Students with Medium and High-Fidelity Simulation: A Randomized Controlled Trial. Nurse Education Today 46.

Basak, Tulay et al. (2016). Beginning and Advanced Students' Perceptions of the Use of Low- and High-Fidelity Mannequins in Nursing Simulation." Nurse education today 36.

Blessing, LT., and Chakrabarti, A. (2014). Drm, a design research methodology. Heidelberg: Springer.

Boling, B., and Hardin-Pierce, M. (2016). "The Effect of High-Fidelity Simulation on Knowledge and Confidence in Critical Care Training: An Integrative Review." Nurse Education in Practice 16(1).

Cummings, L., and Connelly, L. (2016). Can Nursing Students' Confidence Levels Increase with Repeated Simulation Activities?. Nurse education today 36.

Franklin, A. et al. (2014). Psychometric testing on the NLN Student Satisfaction and Self-Confidence in Learning, Simulation Design Scale, and Educational Practices Questionnaire using a sample of pre-licensure 
novice nurses. Nurse Education Today, 34(10).

Fox-Robichaud AE., and Nimmo GR. (2007). Education and simulation techniques for improving reliability of care.Curr Opin Crit Care, 13(6).

Gates, M.G. et al. (2012). Enhancing knowledge using High Fidelity Simulation . Journal of Nursing education , $51(1)$.

Haskvitz, Leah M, and Elizabeth C Koop. (2004). Students Struggling in Clinical? A New Role for the Patient Simulator. Educational Innovations, 43(4).

Jaffer, U. et al. (2015). The effect of a simulation training package on skill acquisition for duplex arterial stenosis detection. J Surg Educ, 72(2).

Jeffries, P. (2007). Simulation in Nursing Education. New York: National League for Nursing.

Jeffries, P., and Rizzolo, M. (2006). Designing and Implementing Models for the Innovative Use of Simulation to Teach Nursing Care of Ill Adults and Children : A National, Multi-Site , Multi-Method Study." National League for Nursing: 1-17.

Kaddoura, M. et al. (2016). Perceived Benefits and Challenges of Repeated Exposure to High Fidelity Simulation Experiences of First Degree Accelerated Bachelor Nursing Students. Nurse education today 36.

Keshk, I., and Mersal, F. (2017). Assessment of Graduate Nurses Entry Level Competencies: Expectations of Faculty Members versus Nurse Managers. American Journal of Nursing Research, 5(1).

King, JM. ( 2012). Nursing Student Satisfaction And Self-Confidence As Related To High Fidelity Simulation. king Saud University. (n.d.). Retrieved from http://ksu.edu.sa/en/about-ksu/history (accessed 10/9/ 2019).

Kirkpatrick, A. et al. (2018). Intraprofessional Simulation's Impact on Advanced Practice and Baccalaureate Student Self-Efficacy. Clinical Simulation in Nursing 16.

Kneebone, R. (2003). Simulation In Surgical Training: Educational Issues And Practical Implication. Wiley Online Library. https://doi.org/10.1046/j.1365-2923.2003.01440.x (accessed 10/9/2019).

Kuznar, K. (2007) Associate Degree Nursing Students perceptions of learning using human patient simulator. Teaching and learning in Nursing, 2(2).

Lestander, Ö. et al. (2016). Nursing Students' Perceptions of Learning after High Fidelity Simulation: Effects of a Three-Step Post-Simulation Reflection Model.” Nurse Education Today, 40.

Levett-Jones, T. et al. (2011). The Development and Psychometric Testing of the Satisfaction with Simulation Experience Scale. Nurse Education Today. http://dx.doi.org/10.1016/j.nedt.2011.01.004. (accessed 10/9/2019).

Lewis, R. et al. (2012). Is High Fidelity Simulation the Most Effective Method for the Development of NonTechnical Skills in Nursing? A Review of the Current Evidence." The Open Nursing Journal, 6.

Li, T. et al. (2018). Baccalaureate Nursing Students' Perspectives of Peer Tutoring in Simulation Laboratory, a Q Methodology Study." Nurse Education Today, 61.

Lioce, L. et al. (2015). Standards of best Practice . Simulation Stabdards IX. Simulation design. Clinical Simulation in Nursing, 11(6).

Lubbers, J., and Rossman, C. (2017). Satisfaction and Self-Confidence with Nursing Clinical Simulation: Novice Learners, Medium-Fidelity, and Community Settings. Nurse Education Today, 48.

Loughran, J. (2002). Effective reflective practice. Journal of Teacher Education, 53(1).

Mariani, B., and Doolen, J. (2016). Nursing Simulation Research: What Are the Perceived Gaps? Clinical Simulation in Nursing, 12(1).

Mortan P. (1995). Creating a laboratory that simulates the critical care environment. Critical Care Nurse, 16.

Mills, J. et al. (2014). Putting it together: Unfolding case studies and high fidelity=tyt simulation in the first year of an undergraduate nursing curriculum. Nurse Education in Pracrice , 14(1).

National League for Nursing. (2016). Descriptions of available instruments. Retrieved from: http://www.nln.org/professional-development-programs/research/tools-andinstruments/descriptionsof-available-instruments. (accessed 10/9/2019).

Nuzhat, A., et al. (2014). Role and challenges of simulation in undergraduate curriculum. Med Teach, 36(1).

Omer, T. (2016). Nursing Students' Perceptions of Satisfaction and Self-Confidence with Clinical Simulation Experience. Journal of Education and Practice, 7(5).

Sawyer, T. et al. (2016). More than one way to debrief: A Critical review of healthcare simulation debriefing methods. Simul Health care, 11.

Schlairet, MC. (2011). Simulation in an undergraduate nursing curriculum: implementation and impact evaluation. Journal of Nursing Education, 50 (10).

Sinclair, B. and Ferguson, K. (2009). Integrating simulated Teaching /learning Strategies in Undergraduate 
Nursing Education. Int. J. Nurs. Educ. Scholarsh, 6(1).

Jeanne, J. (2008). High-Fidelity Simulation in Nursing Education: Design Characteristics and Their Effect on Student Satisfaction and Self-Efficacy (Doctoral Dissertation). ProQuest. https://pqdtopen.proquest.com/doc/304539964.html?FMT=ABS (accessed 10/9/2019).

Tosterud, R. (2015). Simulation Used as a Learning Approach in Nursing Education Students' Experiences and Validation of Evaluation Questionnaires Simulation Used as a Learning Approach in Nursing Education. http://www.diva-portal.org/smash/record.jsf?pid=diva2\%3A760893\&dswid=6228 $\quad$ (accessed 10/9/2019)

Tosterud, R. et al. (2013). Nursing students' perceptions of high- and low-fidelity simulation used aslearning methods. Nurse Education in Practice, 13(4).

Tutticci, N. et al. (2016). High-Fidelity Simulation: Descriptive Analysis of Student Learning Styles." Clinical Simulation in Nursing, 12(11).

Unver, V.et al. (2017). The reliability and validity of three questionnaires: the "Student Satisfaction and SelfConfidence in Learning Scale", "Simulation Design Scale" and "Educational Practices Questionnaire”. Contemp. Nurse, 53(1).

Weaver, A. (2011). High-Fidelity Patient Simulation in Nursing Education: An Integrative Review. Nursing Education Perspectives, 32(1).

Woodruff, K. et al. (2017). Exploring APN Students' Perceptions, Self-Confidence, and Satisfaction With Clinical Simulation. Nursing education perspectives 38(6).

Zapko, K. et al. (2018). Evaluating Best Educational Practices, Student Satisfaction, and Self-Confidence in Simulation: A Descriptive Study. Nurse Education Today, 60.

Zhu, F., and Wu, L. (2016). The Effectiveness of a High-Fidelity Teaching Simulation Based on an NLN/Jeffries Simulation in the Nursing Education Theoretical Framework and Its Influencing Factors. Chinese Nursing Research, 3(3). 